\title{
Friends and Family: How In-Group-Focused Promotions Can Increase Purchase
}

\author{
Karen Page Winterich • Vikas Mittal • \\ Vanitha Swaminathan
}

Published online: 22 August 2014

(C) Springer Science+Business Media New York 2014

\begin{abstract}
Firms use large majorities of their budgets on sales promotions such as coupons and sales events. Many of these sales promotions are framed as "friends and family" or "preferred customer." Which of these frames is more effective, when, and why? We answer these questions building on existing research on deal exclusivity. We show that the success of promotions framed as in-group vs. self-focused depends on whether they are targeted toward interdependent or independent customers. We find that interdependent customers are more receptive to in-group-focused promotions because they perceive such promotions as being higher-value deals. We also show that consistency with brand personality matters: the benefit of in-group-focused promotions for interdependent consumers is higher for brands with a group-oriented personality. Overall, these results show how sales promotions can be more effective without having to increase the magnitude of the promotion.
\end{abstract}

Keywords Sales promotions · In-group focus · Self-focus · Self-construal · Deal evaluation · Group-oriented brand personality

\footnotetext{
K. P. Winterich $(\square)$

Smeal College of Business, Pennsylvania State University, 449

Business Building, University Park, PA 16802, USA

e-mail: kpw2@psu.edu

V. Mittal

Jones Graduate School of Business, Rice University, 6100 Main

Street, Houston, TX 77005, USA

e-mail:vmittal@rice.edu

V. Swaminathan

Katz Graduate School of Business, University of Pittsburgh,

Pittsburgh, PA 15260, USA

e-mail: vanitha@katz.pitt.edu
}

Promotions such as deals and coupons can consume 25 to $50 \%$ of a company's marketing budget $[6,31]$. While increasing the deal magnitude of a promotion (e.g., price cut and coupon value) increases purchase intentions $[19,32]$, the magnitude of impact that a unit increase in deal magnitude of the promotion (i.e., 15 to $20 \%$ ) has on purchase intentions may be context dependent. For instance, Inman et al. [16] find that purchase intentions are increased for products on display even without a price cut. Raghubir [29] finds that when price information is present, a $39 \%$ increase in coupon value (from $\$ 23$ to $\$ 32$ ) increased deal evaluations only by $11 \%$. More recently, Raghubir [30] demonstrated that doubling the coupon value from $\$ 2$ to $\$ 4$ had no effect on deal evaluation. Thus, while increasing the promotion's deal magnitude is very costly from a budgetary perspective, its efficacy in terms of enhancing consumer's deal evaluation and subsequent purchase is limited.

What may be another, more effective and less costly way to enhance the efficacy of such promotions? There is research showing that simply framing the discount value or the redemption window can differentially influence promotion effectiveness [11, 20, 22]. More recently, Barone and Roy [8] demonstrated the effect of deal exclusivity, promotions provided to one person vs. many, on promotion response. These results suggest that framing promotions based on noneconomic dimensions, in a context-specific manner, can make them more effective.

Adding to this research, we specify in-group (vs. selffocused) promotions as a type of promotion framing that can differentially increase the effectiveness of promotions of the same monetary value. When a promotion is in-group focused, it calls attention to the customer being included as part of a larger group (e.g., friends and family); by contrast, when a promotion is self-focused it calls attention to a customer being an individual who is different from others (exclusively for you). We demonstrate benefits from in-group-focused 
promotion frames for consumers based on their own value of the in-group (i.e., individuals' construal of self). More generally, this research makes three contributions. First, we introduce in-group- vs. self-focused promotion framing as a key factor influencing responses to promotions. Second, we suggest that self-construal and in-group (vs. self-focused) promotion framing jointly impact purchase intentions. Third, we identify a boundary condition for these effects (i.e., grouporiented brand personality) that is of both theoretical and practical importance. We report three studies. Study 1 examines the joint impact of self-construal and promotion framing on purchase intentions by measuring chronic self-construal. Study 2 replicates the effect found in study 1 with primed situational self-construal and demonstrates the mediating role of deal evaluation. Study 3 extends the prior two studies by demonstrating the moderating role of brand personality needed to obtain the benefit of in-group promotion framing for interdependent consumers.

\section{Theory and Hypotheses}

Framing effects occur when logically equivalent descriptions lead to different responses and have been robustly shown for promotions [22]. Most studies in the promotions literature have focused on framing the discount value (e.g., "50 \% off" or "buy 1, get 1 free"; see [33]) in monetarily equivalent ways. More recent research has framed the exclusivity of promotions; for instance, "by invitation only" as exclusive promotions vs. "open to the general public" as inclusive promotions. Results show, while consumers generally tend to prefer more exclusive promotions, those with an interdependent selfconstrual respond more favorably to an inclusive (vs. exclusive) promotion, the opposite occurs for independent consumers [8].

We examine promotions framed as being in-group or selffocused, while holding the monetary value of the promotions constant. As explained earlier, promotions can be framed as in-group focused ("friends and family" where a customer is included as part of an in-group) or self-focused ("for you" where an individual customer is the only focus). Stated differently, in-group-focused promotions attempt to highlight the consumer's similarity to other members of a group associated with the brand (e.g., friends and family sale or employee discount). By contrast, self-focused promotions emphasize the uniqueness of the individual consumer (e.g., birthday discount or preferred customer sale). Of course, self-focused promotions may be offered to more than one customer (i.e., there are numerous preferred customers or everyone with a birthday in that month receives that month's birthday promotion); the crucial point is that a self-focused promotion is framed to highlight the customer as an individual. As shown in Appendix 1, both types of promotions have become increasingly popular in recent years. Retailers may frame their "percentage-off" discounts as "friends and family sales" or "employee discounts." Christopher \& Banks Corp. attributed a $22 \%$ increase in same-store sales to its friends and family promotional offer-an in-group-focused promotion [41].

\subsection{Joint Effect of Promotion Frame and Self-Construal}

Self-construal reflects the extent to which individuals perceive themselves as separate from or connected to others [23]. Those with an interdependent self-view base their attitudes and behavior on the thoughts, feelings, and actions of others in the relationship [23]. Conversely, those with an independent self-construal base their attitudes and behavior on their own internal repertoire of thoughts, feelings, and actions, rather than others' thoughts, feelings, and actions [23]. In many marketing contexts, self-construal can be situationally activated $[3,15]$ and play a strong part in influencing consumer's brand meaning and evaluations $[14,36]$, the persuasiveness of advertising appeals $[2,3]$, as well as the ability of a brand to successfully expand into other product categories [4].

While self-construal has often been considered to represent a self vs. other orientation, more recent research has demonstrated that the other orientation that characterizes an interdependent self-construal is specific to the in-group. For example, while research found a positive correlation between interdependence and charitable behavior [25, 39], more recent work has demonstrated that interdependents are more likely to help needy in-group members whereas independents are equally likely to help in- and out-group members in need [13]. These findings are consistent with work demonstrating that females tend to start with a focus on the in-group in their decision making whereas males start with a focus on the self, which were also replicated with self-construal [40]. As such, the previously identified "matching" effect of self-construal (i.e., interdependents $=$ other focus and independents $=$ self-focus) reflects the notion that the effect of self-construal applies more strongly for in-group-focused options but is less differentiating for self-focused options. For example, consider the moderating role of self-construal on the effect of deal exclusivity identified by Barone and Roy [8]. They found that consumers with an independent self-construal preferred exclusive deals more than those with an interdependent self-construal whereas those with an interdependent self-construal preferred inclusive offers more than exclusive deals, consistent with a selfconstrual-promotion matching effect. However, when closely examined, the effect of self-construal is stronger for inclusive deals than exclusive deals. As such, we too consider the extent 
to which self-construal may impact the effectiveness of ingroup-focused promotions but not self-focused promotions.

To support this theorizing, recall that in-group-focused promotions (e.g., friends and family discounts) emphasize consumers' relationships with those in the customer's ingroup. Notably, going beyond the self, an in-group-focused promotion relates the customer to those in-group members with whom one would reasonably associate [14]. Thus, this in-group promotion frame is consistent with the focus of interdependent consumers. However, for independent consumers, this in-group-focused promotion frame does not resonate, because their focus is on the self. According to the benefit-congruency framework [10], congruency between consumer self-construal and promotion frame is likely to directly increase purchase intentions. Based on our logic, the in-group promotion is viewed more favorably by interdependent consumers than independent; as such, interdependent consumers should evaluate the deal more positively [31]. The positive deal evaluation in turn should increase purchase intentions among interdependent consumers relative to independent consumers [17].

On the other hand, a self-focused promotion emphasizes the importance of the individual consumer. While independent consumers naturally tend to have a greater focus on the self, in the case of sales promotions, interdependent consumers should also be receptive to a promotion highlighting the self. As such, self-focused sales promotions are not expected to strongly resonate or "match" with consumer's self-construal. If there is not particular congruence with one type of selfconstrual (independent or interdependent) for the self-focused promotion, then all consumers should evaluate the deal similarly regardless of self-construal, resulting in similar purchase intentions. More formally, we hypothesize the following:

H1: Promotion frame and self-construal will jointly impact purchase intentions such that for an in-group focused promotion, interdependent consumers will have higher purchase intentions than independent consumers. In contrast, for a self-focused promotion, self-construal will not impact purchase intentions.

\subsection{Mediating Role of Deal Evaluation}

The literature on promotions shows that the increase in purchase intentions results from enhanced perceptions of deal evaluations [17, 29]. Research has established that nonmonetary (e.g., psychological) benefits influence brand choice as well [10, 32]. For example, Barone and Roy [9] found that the effectiveness of exclusive promotions was dependent on the ability for consumers to engage in selfenhancement.

However, what is absent is a theoretical and empirical examination of whether or not such psychological, nonmonetary aspects of a promotion can affect more cognitive evaluations of promotions, i.e., deal evaluations. In other words, an unstated (and untested) assumption is that deal evaluation is largely a function of monetary benefits, and nonmonetary benefits affect purchase intentions directly. We argue that deal evaluations are influenced by the nonmonetary, psychological benefits as well because consumers' perceptions of the deal rely on psychological factors in addition to economic factors [31]. As such, when consumers' construal of self is (in)congruent with the in-group promotion frame, interdependent (independent) consumers will perceive the deal to be better (worse). The increased deal evaluations will result in greater purchase intentions for in-group-focused promotions offered to interdependent consumers whereas such effects will not occur for self-focused promotions since the congruence with self-construal is weaker. These arguments suggest that deal evaluations will mediate the effect proposed above, which is formally stated below:

H2: Deal evaluations will mediate the joint effect of selfconstrual and promotion frame on purchase intentions.

\subsection{Moderating Role of Group-Oriented Brand Personality}

Chandon et al.'s [10] benefit-congruency framework suggests that the effectiveness of sales promotions is determined by the congruency between the promotion's benefits and those of the promoted brand. Thus, in addition to our proposed hypothesis that the promotion's benefits are dependent on the promotion's congruency with the consumer's self-view, we examine how a brand's personality-group or individual orientedmoderates the above relationship.

More generally, past research has demonstrated that sales promotions are not equally effective across brands or product categories [7, 35, 38]. We focus on congruency with a specific brand personality aspect - whether or not a brand is seen as being group or individual oriented. For example, a grouporiented brand would cater to families or seek to foster a common interest among a group of people (i.e., runners, female teen fashionistas, and middle-aged outdoor enthusiasts). By contrast, an individual-oriented brand would help individuals differentiate themselves from others. We propose that a group-oriented brand personality will moderate the effect of promotion frame and self-construal on purchase intentions. For brands that have a group-oriented personality, the in-group promotion frame will be congruent with the 
brand personality, resulting in increased purchase intentions among interdependent consumers relative to independent consumers. However, for brands that do not have a group-oriented brand personality, the joint effect of promotion frame and selfconstrual will be attenuated due to the lack of congruence between the in-group promotion frame but low group-oriented brand personality. Thus, we hypothesize the following:

H3: Group-oriented brand personality will attenuate the effect of self-construal for in-group promotion frame on purchase intentions such that the increase in purchase intentions from an in-group promotion frame among interdependent consumers will only occur for brands with a group-oriented brand personality.

\section{Pilot Study}

Though prior research has examined deal exclusivity, defined as a continuum ranging from promotions provided to one person to offers that are available to virtually all consumers in a market, by Barone and Roy [8], we first sought to determine whether consumers perceive exclusive promotions distinct in the extent to which they are in-group vs. selffocused.

Ninety-eight undergraduate students were asked to evaluate one of five promotion frames. The five promotion frames were: friends and family, employee, preferred customer, birthday discount, and sale (control). We anticipated that participants would perceive friends and family and employee promotions as in-group focused. By contrast, preferred customer and birthday promotions would be perceived as self-focused. After viewing one of the five promotions, each participant responded to six randomly ordered statements (see Appendix 2) regarding the extent to which the promotion made them focus on the in-group or the self. Responses were on a 7 -point scale ( $1=$ strongly disagree, $7=$ strongly agree) . Three items for in-group focus were averaged to form an ingroup score $(\alpha=0.84)$ and three items for self-focus were averaged to create a self-focused score $(\alpha=0.83)$.

First, neither specific in-group promotion type (friends and family and employee) nor specific self-focused promotion type (birthday and preferred customer) significantly impacted perceived in-group or self-focus, respectively $(p>0.10)$. As such, promotion type was collapsed such that the two in-group promotions were in one category and the two self-focused promotions created the second category with the control condition a third category. An ANOVA of the three promotion frames on in-group focus revealed a significant effect of promotion frame $(F(2,95)=5.38$, $p<0.01)$. Specifically, in-group promotions $(M=4.22)$ were perceived to be significantly more in-group- than self-focused promotions $(M=3.65, t=2.02, p<0.05)$ and the control promotion $(M=2.95, t=3.16, p<0.01)$. Selffocused promotions were perceived as marginally more in-group focused than the control $(t=1.79, p=0.08)$. By contrast, self-focused promotions $(M=4.55)$ were perceived to be significantly more self-focused than ingroup-focused promotions $(M=3.75, t=3.00, p<0.01)$ and the control promotion $(M=3.05, t=4.07, p<0.01)$. Ingroup-focused promotions were perceived as marginally more self-focused than the control $(t=1.87, p=0.06)$. These results are summarized in Table 1.

Discussion Consumers perceive friends and family and employee discounts as in-group focused whereas promotions such as preferred customer and birthday discounts are perceived to be self-focused. We used promotion frames that are frequently offered by companies to increase realism (see Appendix 1). However, it is important to note that because these promotions did not occupy the endpoints of the continuum, our studies provide a conservative test of promotion framing effects.

\section{Study}

To test hypothesis 1 , study 1 examines the effect of promotion framing and chronic self-construal on purchase intentions.

Participants A total of 425 undergraduates at a large North American university participated in the study for course credit. Among them, $44 \%$ were female with an average age of 21.11 years $(\mathrm{SD}=1.36$, range $=19$ to 30$)$. Neither gender nor age affects the dependent variable and is not discussed further.

Design and Procedure The study was a 3 (promotion: ingroup, self-focused, and control) $\times$ continuous (self-control)

Table 1 Pilot study: perceived in-group and self-focus of promotions

\begin{tabular}{lll}
\hline & $\begin{array}{l}\text { Perceived } \\
\text { in-group focus }\end{array}$ & $\begin{array}{l}\text { Perceived } \\
\text { self-focus }\end{array}$ \\
\hline $\begin{array}{lll}\text { In-group-focused promotions (I) } \\
\text { (friends and family, employee) }\end{array}$ & $4.22 \mathrm{SC}$ & $3.75 \mathrm{~S}$ \\
$\begin{array}{c}\text { Self-focused promotions (S) } \\
\text { (preferred customer, birthday) }\end{array}$ & $3.65 \mathrm{I}$ & $4.55 \mathrm{IC}$ \\
Control (C) & $2.95 \mathrm{I}$ & $3.05 \mathrm{~S}$ \\
\hline
\end{tabular}

Note: upper case letters indicate significance, $p<0.05$ 
between-subject design with self-construal measured. The survey was conducted in two parts. First, each participant completed a brand-opinion survey at the beginning of a 1hour research session. Participants then completed various other unrelated questionnaires regarding product preferences and quality evaluations. With approximately $5 \mathrm{~min}$ remaining in the session, participants were given a coupon for a local gift and apparel retailer and asked to respond to purchase intention and deal evaluation measures. Participants' evaluations were made in regard to the store brand (i.e., retail brand).

\subsection{Measures}

Self-Construal Participants completed the entire Singelis [34] scales for independent (12 items, $\alpha=0.67$ ) and interdependent (12 items, $\alpha=0.69$ ) chronic self-concepts. We create a continuous index of the degree of interdependence relative to independence for each individual. Creating the index allows us not only to retain all participants, but it also provides a more conservative and realistic test of the hypothesis given that the majority of consumers cannot be classified solely as independent or interdependent. Following Escalas and Bettman [14], the index was constructed using the Singelis [34] scales as follows (interdependent-independent)/(interdependent + independent). On this index, higher scores indicate greater interdependence relative to independence.

Promotion Frame Based on their randomly assigned condition, participants received one of three promotions: an ingroup (family sale), self-focused (preferred customer sale), or control (sale) coupon.

Purchase Intentions Participants responded to the following two items on a 7-point scale ( $1=$ strongly disagree, $7=$ strongly agree) to measure purchase intentions: "I am likely to purchase something from this store," and" I will buy something from this store." These two items were measured in the brandopinion survey at the start of the research session and following exposure to the coupon $\left(r_{\text {pre-exposure }}=0.88, r_{\text {post-exposure }}=\right.$ $0.85)$. Pre-exposure purchase intentions and purchase intentions following exposure to the stimuli were measured consistent with research measuring pre- and post-brand attitude $[5,36]$. Pre-exposure purchase intentions are included as a covariate in our analysis. Excluding pre-exposure purchase intentions in this analysis or analyses reported in subsequent studies does not alter the results.

\subsection{Results}

Purchase Intentions A regression analysis was conducted with all variables centered prior to analysis to minimize multicollinearity between these variables and their interactions (all VIFs $<5$ ). Self-construal (continuous measure), promotion frame (self-focused $=-1$, control $=0$, and in-group $=1$ ), and their interaction were the independent variables. Purchase intentions were the dependent variable, and pre-exposure purchase intentions were included as a covariate. The overall model was significant $(F(4,420)=33.45, p<0.01)$. As expected, pre-exposure purchase intentions were significant $(\beta=$ $0.40, p<0.01)$. The effect of promotion type was not signifi$\operatorname{cant}(\beta=0.00, p>0.99)$ nor was the effect of self-construal $(\beta=$ $0.14, p=0.11)$. Importantly, the two-way interaction was significant $(\beta=0.25, p=0.02)$. This pattern is illustrated in Fig. 1 .

We further analyze the two-way interaction by examining the effect of self-construal within each promotion frame. First, for in-group-focused promotion, self-construal had a significant, positive effect $(\beta=0.34, p<0.01)$ such that higher interdependence increased purchase intentions. For the selffocused promotion, self-construal did not have an effect $(\beta=$ $-0.07, p=0.57)$. Similarly, in the control condition of a regular sale coupon, there was no effect of self-construal $(\beta=0.14, p=$ $0.11)$. This pattern supports hypothesis 1 and is presented in Fig. 2.

Discussion These findings support hypothesis 1, indicating that purchase intentions are greater among interdependents when the promotion is in-group focused whereas effects of self-construal do not occur for self-focused or regular sale (control) promotions. Note that participants actually received the coupon and had the opportunity to shop at the local retailer so purchase intentions are likely to reflect actual behavior. To provide a stronger and cleaner theoretical test as well as determine if this pattern replicated for situationally activated self-construal, we prime self-construal in the next study. We

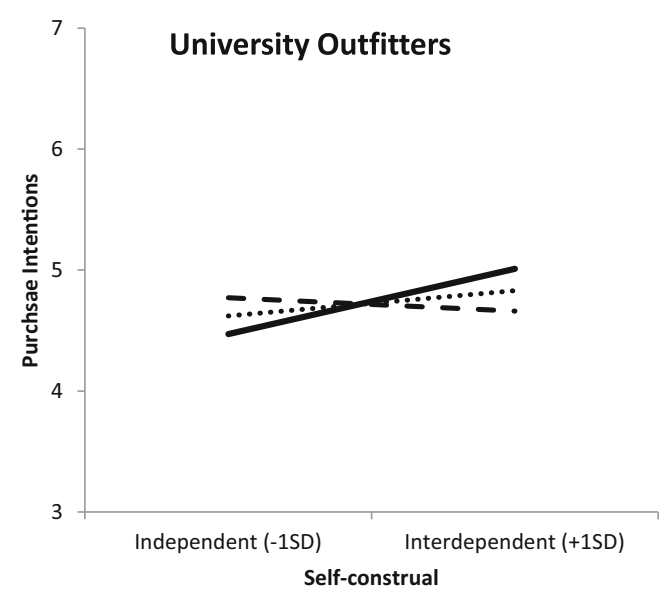

- Self-focused ...... Control In-group focused

Fig. 1 Study 1: effect of measured self-construal and promotion frame on purchase intentions 


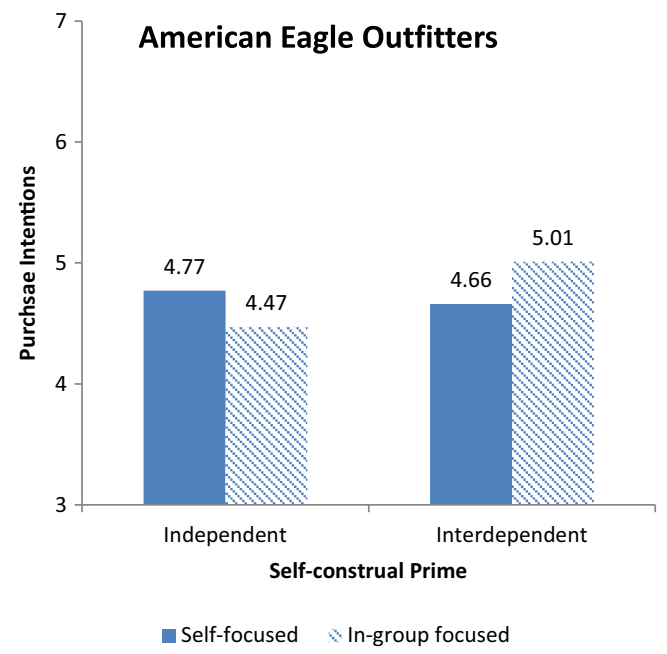

Fig. 2 Study 2: effect of primed self-construal and promotion frame on purchase intentions

focus only on in-group- vs. self-focused promotions in the subsequent studies.

\section{Study 2}

In study 2, we prime self-construal to replicate the effect found for chronic self-construal in study 1 and provide further support for hypothesis 1 . We also examine deal evaluation to test the mediation proposed in hypothesis 2 . Additionally, we use an employee discount for the in-group-focused promotion condition and a birthday discount for the self-focused promotion condition and examine purchase intentions using a real national apparel retailer rather than a local retail brand to enhance generalizability to different promotions and brands.

\subsection{Method}

Participants A total of 116 undergraduates at a large North American university participated in the study for course credit. Of participants, $57 \%$ were female with an average age of 20.63 years $(\mathrm{SD}=1.31$, range $=18$ to 29$)$. Neither gender nor age has an effect and is not discussed further.

Design and Procedure The study was a 2 (primed self-construal: interdependent vs. independent) $\times 2$ (promotion: ingroup vs. self-focused) between-subjects design. First, participants completed a brief brand-opinion questionnaire at the beginning of a 1-h research session to measure pre-exposure purchase intentions. Approximately $30 \mathrm{~min}$ later, participants completed the self-construal prime and were then shown the promotion. The self-construal prime was presented as a writing assessment study. Immediately after this study, participants were asked to complete a consumer decision study in which they viewed one of the two promotion frames and indicated their purchase intentions, deal evaluations, and background information.

Participants were shown either an in-group- (employee discount) or a self-focused (birthday discount) promotion (see Appendix 3), depending on their randomly assigned condition. The pilot study confirmed these promotions were perceived to be in-group and self-focused, respectively. Purchase intentions were measured with the same two items used in study 1 ( $r_{\text {pre-exposure PI }}=0.92, r_{\text {post-expo- }}$ sure $\mathrm{PI}=0.91)$. For measuring deal evaluations, we followed Raghubir [29]. Participants responded to three items regarding their evaluation of the promotion: "This deal is attractive to me," "This is a valuable offer," and "This is a good deal." Responses were on a 7-point scale $(1=$ strongly disagree, $7=$ strongly agree) and were averaged to create an index $(\alpha=0.89)$.

Self-Construal Self-construal was manipulated using the method proposed by Trafimow et al. [37]. Participants were asked to take a few minutes to think about how they are different from (independent) or similar to (interdependent) their family and friends. Following the induction, participants were asked to complete ten 'I am" statements to describe themselves, as a manipulation check [21]. Two graduate students unaware of the hypotheses coded statements as independent, interdependent, or neither (79\% agreement). Participants in the independent condition wrote significantly more independent statements ("I am smart and" "I am strong,") than those in the interdependent conditions ( $M=$ 7.18 vs. $6.39, t=2.30, p<0.05$ ). Conversely, participants in the interdependent condition wrote significantly more interdependent statements ("I am a student" and "I am a sister") than those in the independent condition ( $M=2.97$ vs. $2.25, t=$ $2.05, p<0.05)$. Importantly, the total number of statements did not differ by self-construal manipulation ( $M=9.04$ vs. 9.00 , $t=0.26$, NS). We acknowledge that these differences may not seem meaningful, but they are consistent with existing research priming self-construal and provide a conservative test of our hypotheses.

To ensure the manipulation of self-construal was orthogonal with other variables, an analysis if covariance (ANCOVA) was conducted for the manipulation check of the independent and interdependent statements. For each ANCOVA, the main effect of the self-construal variable was significant $(p<0.05)$. Importantly, neither promotion frame nor the interaction was significant $(p>0.05)$, indicating that self-construal was orthogonal with the promotion frame. 


\subsection{Results}

Purchase Intentions An ANCOVA was conducted with primed self-construal, promotion frame, and their interaction included as independent variables, purchase intentions as the dependent variable, and pre-exposure purchase intentions as a covariate. The overall model was significant $(F(4,111)=$ $31.45, p<0.01)$. As expected, pre-exposure purchase intentions were significant $(\beta=0.59, p<0.01)$. The effect of promotion type was not significant $(\beta=-0.03, p>0.82)$ nor was the effect of self-construal $(\beta=0.15, p=0.21)$. Importantly, the two-way interaction was significant $(\beta=0.35, p<0.01)$.

We further analyze the two-way interaction by examining the effect of self-construal within each promotion frame. First, for in-group-focused promotion, self-construal had a significant, positive effect $(\beta=0.50, p<0.01)$ such that consumers primed with interdependence reported higher purchase intentions than those primed with independence. For the selffocused promotion, self-construal did not have an effect ( $\beta=$ $-0.20, p=0.21$ ). This pattern supports hypothesis 1 and replicates the results of study 1. This pattern is presented in Fig. 2.

Mediating Role of Deal Evaluation To examine the mediating role of deal evaluation, we used bootstrapping [28, 43]. Selfconstrual, promotion frame, and their interaction were the independent variables, pre-exposure purchase intentions were included as a covariate, and purchase intentions were the dependent variable with deal evaluations as the mediator. The results indicated that the $95 \%$ confidence interval of the indirect effect from the interaction term to purchase intentions through deal evaluations did not include zero (indirect effect= $0.24, \mathrm{SE}=0.08 ; 95 \% \mathrm{CI}, 0.10$ to 0.41 ), providing evidence of mediation. For the in-group promotion, the indirect effect of self-construal through deal evaluations was positive and significant (indirect effect $=0.25, \mathrm{SE}=0.12 ; 95 \% \mathrm{CI}, 0.04$ to $0.50)$. By contrast, when the promotion was self-focused, the indirect effect was not significant (indirect effect $=-0.23, \mathrm{SE}=$ $0.10 ; 95 \% \mathrm{CI},-0.42$ to 0.03 ). Thus, as proposed in hypothesis 2 , the hypothesized effect is mediated via deal evaluation.

Discussion The results of this study replicate those of study 1 when priming self-construal rather than measuring chronic self-construal. We expand the examination of self-focused promotions from preferred customer discounts to include birthday discounts and still find a null effect of self-construal for the self-focused promotion but a significant effect for the in-group promotion frame. The mediating role of deal evaluation is also confirmed.

Having replicated the focal effect, the next study seeks to demonstrate a boundary condition of both theoretical and practical importance. Theoretically, if the effect is due to the congruency between the in-group focus and interdependent consumers, then a stronger test of this congruency effect would be to demonstrate that the effect can vary based on a contextual factor that can facilitate or mitigate this congruency. The extent to which a brand's personality is group or individual oriented is one such contextual factor.

\section{Study 3}

Brands differ in whether their personality is perceived to be more group or individual oriented. For example, a grouporiented brand may emphasize a common interest among a group of people, whereas an individual-oriented brand may help consumers differentiate themselves. We propose that the effectiveness of matching in-group promotions with consumer self-construal will be particularly pronounced for brands with a relatively strong group-oriented personality while effects will be attenuated for brands with a weak group-oriented brand personality. Given the null effects of self-construal on self-focused brands in prior studies, this study focuses on an in-group, friends and family, promotion.

\subsection{Method}

Participants A total of 149 undergraduates at a large North American university participated in the study for course credit. Of participants, $46 \%$ were female with an average age of 21.02 years $(\mathrm{SD}=0.96$, range $=19$ to 25 ). Neither gender nor age has an effect and is not discussed further.

Design and Procedure The study was a 2 (group-oriented brand personality: high vs. low) $\times$ continuous (self-construal) between-subjects design. Participants were randomly assigned to one of the two brand conditions, Old Navy for high grouporiented brand personality and Express for low group-oriented brand personality. Participants viewed a $20 \%$ off on friends and family promotion for the corresponding brand. They were asked to view and evaluate the brand promotion. Purchase intentions were assessed with three items: "I am likely to purchase something from this store," "I will buy something from this store with this discount," and "I would definitely shop at this store because of this offer." Responses were on a 9-point Likert scale (1= strongly disagree to $9=$ strongly agree) and were averaged to form the purchase intention index $(\alpha=0.95)$. Then, they were asked to complete various personality questionnaires, which included the Singelis [34] self-construal measure used in study 1 (interdependent: $\alpha=0.75$, independent $\alpha=0.73$ ).

The two brands were selected from a pretest ( $n=80$ undergraduate students) of eight well-known clothing brands 
among undergraduates. The pretest determined that Old Navy and Express were two clothing brands that were similar on several factors. Specifically, these two brands did not differ in brand attitude $\left(M_{\text {Express }}=6.46\right.$ vs. $M_{\text {OldNavy }}=6.99, t=1.27, p=$ $0.21)$, frequency of shopping $\left(M_{\text {Express }}=3.58\right.$ vs. $M_{\text {OldNavy }}=$ $4.20, t=1.43, p=0.16)$, or brand commitment $\left(M_{\text {Express }}=2.55\right.$ vs. $M_{\text {OldNavy }}=2.85, t=1.03, p=0.30$ ). Thus, we used these two brands.

A manipulation check verified they differed on grouporiented brand personality. Specifically, participants responded to two items regarding group-oriented brand personality $(r=0.87$, $p<0.01)$ : "This brand makes me feel like one of the group," and "This brand makes me feel included." Results indicated that the brand personality of Old Navy $(M=4.71)$ was more group oriented than Express $(M=4.20, t(147)=2.01, p<0.05)$.

\subsection{Results}

Purchase Intentions A regression analysis was conducted with all variables centered prior to analysis to minimize multicollinearity between these variables and their interactions (all VIFs <2). Self-construal, brand personality (low group oriented $=0$, high group oriented $=1$ ), and their interaction were the independent variables. Purchase intentions were the dependent variable. The overall model was significant $(F(3,145)=3.22, p<0.05)$. Neither main effect was significant, but the two-way interaction was significant $(\beta=3.28$, $p<0.02$ ).

We further analyze the two-way interaction by examining the effect of self-construal within high and low levels of group-oriented brand personality. For the high grouporiented brand (Old Navy), the effect of self-construal was positive and significant $(\beta=6.77, t=2.91, p<0.01)$ such that higher interdependence results in greater purchase intentions. By contrast, for the low group-oriented brand (Express), the effect of self-construal was not significant $(\beta=-0.83, t=0.36$, $p=0.72$ ) such that self-construal does not impact purchase intentions, supporting hypothesis 3 . This pattern is presented in Fig. 3.

Discussion This study demonstrates that when an in-group promotion is inconsistent with the brand's personality, the ingroup promotion is ineffective regardless of consumer selfconstrual. Thus, an in-group promotion frame only enhances purchase intentions when the in-group promotion frame is compatible with construal of self as well as brand personality (i.e., group oriented). One question may be whether this pattern is consistent with promoted brands in studies 1 and 2 . Importantly, the retailer in study 1 was a university-relevant retailer and thus is characterized by a group-oriented brand personality. Additionally, a post-test confirmed that AEO, used in study 2, was perceived to have a group-oriented brand

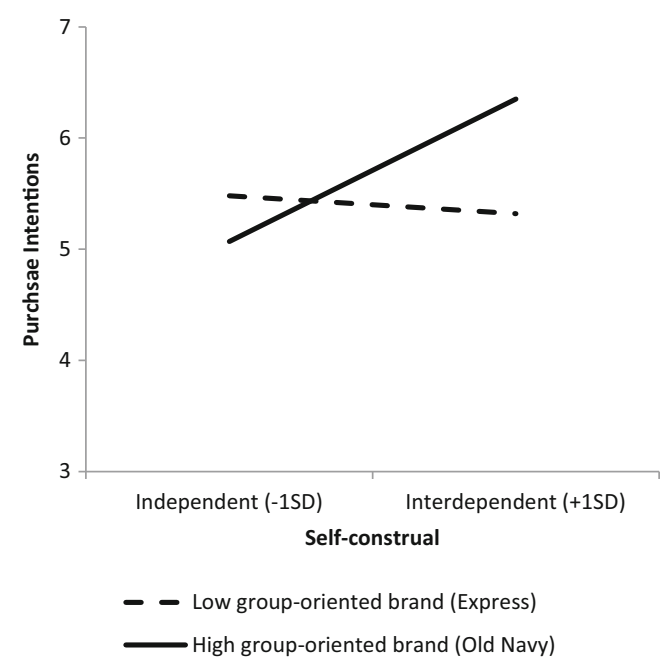

Fig. 3 Study 3: effect of measured self-construal and group-oriented brand personality on purchase intentions

personality $(M=4.75)$ equal to that of Old Navy $(M=4.71)$. Thus, our results are consistent with findings in studies 1 and 2 .

\section{General Discussion}

Promotions consume a significant part of marketing budgets and are a key tool in a firm's arsenal to affect sales. We show how managers can improve the perceived efficacy of promotions by framing them as either in-group focused or selffocused. We demonstrate that only in-group-focused promotions benefit from congruency with the consumer's selfconstrual (chronic or activated): purchase intentions are greater for interdependent consumers than independents. This finding emerges for different types of in-group promotions (e.g., employee or friends and family discounts). Self-construal does not impact purchase intentions when a self-focused or control promotion is offered. Thus, our research articulates the importance of congruency between self-construal and promotion frame in enhancing promotion effectiveness, but in a nuanced manner.

Our research also addresses two additional, but important issues. First, we show how this joint effect manifests only for brands with congruent brand personality. Second, deal evaluation mediates the observed pattern of effects, suggesting that purchase intentions are not directly influenced by self-construal and promotion frame congruency but that they are increased because consumers perceive the deal more favorably. This finding indicates the importance of influencing consumer deal evaluations to increase sales rather than directly increasing sales. Although not examined here, the more favorable deal evaluations formed under self-construal and promotion frame congruency 
may impact long-term brand attitude, mitigating the potentially negative effects of price promotions on brand equity $[1,42]$.

\subsection{Contribution to Theory}

Raghubir et al. [31] call for research which examines how promotion effectiveness can be increased without increasing discount value. We do so by showing that congruence between a consumer's self-concept and promotion frame can improve promotion efficacy. This also extends the benefit-congruency framework [10] by showing that nonmonetary, psychological benefits of promotions are enhanced when self-construal goals are congruent with the frame of the promotion. Thus, in addition to promotionproduct congruence, promotion effectiveness can be enhanced through promotion self-congruence. Notably, this research moves beyond the typical matching effects identified for self-construal with marketing stimuli $[2,3,14$, 36].

This research builds on the promotions literature focusing on the three routes for promotion effectiveness by recognizing that self-construal influences the nonmonetary, psychological benefits influencing promotion effectiveness [31]. In this regard, prior conceptualizations suggest that deals framed in terms of self-concept become more attractive of psychological benefits such as selfenhancement [9]. Ours is the first study to show that deals framed in terms of self-concept can become more attractive because of economic benefits, such as deal evaluation. This is an important finding because it suggests that deals can actually be seen as more attractive, in financial terms, because of simple psychological framing and matching with self-concept.

Lastly, by showing the prominent role of brand personality, our research also shows that managers cannot and should not use such a strategy indiscriminately. Rather, such a strategy of matching the promotion frame to customers' interdependent self-concept is likely to succeed only when brand personalities are group oriented. One important theoretical implication stems from the fact that all the studies reported in this research were conducted in the USA, a relatively independent society. Yet, we found that an interdependent self-construal coupled with an ingroup-focused promotion was more efficacious than a self-focused promotion. On first blush, this may seem counterintuitive as one would expect a self-focused promotion to be more successful in the USA. One concern may be that the null effect of self-construal for selffocused promotions is specific to consumers with chronic independence. However, we replicated the effect of selfconstrual on in-group-focused promotions when self- construal was measured as a chronic self-view as well as when it was temporarily activated. Moreover, the benefits of in-group focus among interdependent consumers have been demonstrated across cultures (i.e., Hong Kong; [13]). We believe the effects of in-group promotions demonstrated in this research may only be stronger in cultures where consumers are characterized by chronic interdependence given the orthogonality of interdependence and independence $[27,26]$.

\subsection{Implications for Managers}

Enhancing promotion effectiveness by increasing discount values directly erodes margins and profitability. Therefore, finding a way to increase promotion effectiveness without increasing discount values and decreasing profit margins is important for managers. Our research provides answers in this regard. Strategically, managers should first understand the self-views of the target consumers and the personality of their brand. If their brand's personality is positioned to be group oriented, and the target consumer tends to have an interdependent selfconstrual, managers can gain additional value from promotions with an in-group focus (i.e., friends and family, employee, etc.). Even when they do not know their customer's self-view or identity, they can use common marketing variables that are strongly related to an interdependent identity [4]. For instance, consumers in East Asian countries [24], ethnic groups such as Asian Americans and Hispanics [26], and female consumers [12, 40] tend to rate higher on interdependent self-construal: as such they are likely to have higher purchase intentions for ingroup-focused promotions such as friends and family sales. Furthermore, through communication and other marketing-mix variables, firms can temporarily activate a customer's interdependent identity to achieve promotion effectiveness. For example, coupons and communications using terms such as "we/us/our" rather than "me/I" can differentially activate an interdependent identity [2].

As our results show, there is a definite need to understand the fit between brand personality and promotion strategy. It takes years for a firm to develop a brand's personality. Study 3 illustrates that marketers will not benefit from offering an ingroup-focused promotion when the brand personality is seen as being less group oriented. It seems that promotions for brands and categories that are focused on families or relationships or a collective group of consumers should be more effective when the promotion is in-group focused. However, if the brand or product emphasizes the consumer's individuality or uniqueness, in-group-focused promotions will not align with the product category or brand personality, minimizing any benefits from the promotion-self-view congruency. 
In regard to coupon value, promotion literature has found that discount value can positively as well as negatively influence promotion effectiveness and brand evaluations [29]. As discussed earlier, this research proposes that promotion effectiveness can be enhanced without increasing monetary value. The current research examines the effect of promotion framing at moderate discount levels of $30 \%$ (studies 1 and 2 ) and $20 \%$ (study 3). Importantly, we do not expect that promotion effectiveness is enhanced when promotion frame is congruent with self-construal at extremely high or low discounts (i.e., 50 or $5 \%$ ). If our results hold for low-discount coupons, then managers can save even more based on our findings. This issue should be examined in future research.

This research focused on promotions for brands with which the sample population was familiar and tended to be current customers. However, past research has found that effects of promotions on purchase may be minimized when consumers do not perceive they have earned the promotion [18], such as based on their past purchase behavior (i.e., low relationship equity, [8]). Thus, it is important to recognize that offering such in-group-focused promotions will likely not be effective for new customers, even if the promotion is congruent with the customer's self-view.

\section{Appendix 1}

Table 2 Sample promotion frames

\section{Appendix 2}

In-group-/self-focused scale

1. The promotion would make me feel like part of the AEO group (in-group)

2. The promotion would make me feel like a member of the AEO family (in-group)

\begin{tabular}{lll}
\hline Company & Sale/e-mail heading & Promotion type \\
\hline Lady Foot Locker & $\begin{array}{l}\text { Save } 30 \% \text { on your holiday shopping at our friends } \\
\text { and family event } \\
\text { Friends and family event starts today }\end{array}$ & In-group \\
Ann Taylor LOFT & Save at the friends and family event & In-group \\
Macy's & You're invited to our friends and family event & In-group \\
JCPenney & Loft loves teachers & In-group \\
Ann Taylor LOFT & An exclusive invite to a special sale & In-group \\
J. Crew & Exclusive event: extra 30 \% off our fall sale & Self-focused \\
J. Crew & Exclusive offer inside & Self-focused \\
Gap & Shop our private sale and enjoy an exclusive discount & Self-focused \\
Hallmark.com & Self-focused \\
Road Runner Sports & Preferred customer sale & Self-focused \\
Best Buy & Preferred customer program & Self-focused \\
Harbor Freight Tools & Best customer sale & Self-focused \\
Macy's & Birthday coupon/discount & Self-focused \\
Ann Taylor LOFT & & Self-focused \\
AVEDA & & \\
Columbia Sportwear & & \\
CVS Pharmacy Beauty Club & & \\
DSW Shoes & & \\
Old Navy & & \\
Payless Shoes & & \\
ToysRUs & & \\
Sephora & & \\
\hline
\end{tabular}

3. This promotion would make me focus on others I care about like my friends and family (in-group)

4. This promotion would make me feel unique from others (self-focused)

5. This promotion would make me focus on myself as an individual (self-focused)

6. This promotion would make me feel like I was getting a discount better than others (self-focused) 


\section{Appendix 3}

Promotions (pilot study and study 2)

In-group-focused promotions

\section{PROMOTIONS (PILOT STUDY AND STUDY 2)}

\section{IN-GROUP FOCUSED PROMOTIONS}

You're Part of the Family! FRIENDS AND FAMILY EMPLOYEE DISCOUNT

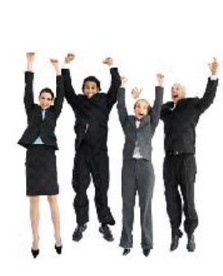

American Eagle Outfitters (AEO) has recently decided to offer its employee discount to their customers. This employee discount will be offered to AEO customers during this event when AEO customers will become part of the AEO family.

This AEO family employee discount offer is a $30 \%$ discount on all items purchased. This $30 \%$ discount will allow AEO customers to shop at $A E O$ during this event and receive the AEO family discount.

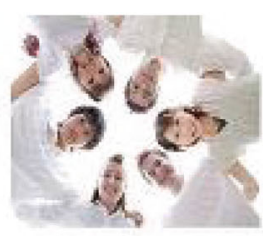

You're Part of the Family! FRIENDS AND FAMILY DISCOUNT

American Eagle Outfitters (AEO) has recently decided to offer a dlscount to thelr customers. This friends and famlily dlscount will be offered to AEO customers during this event when AEO customers will become part of the AEO family.

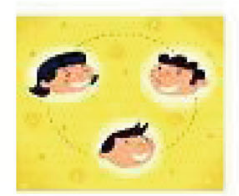

This AEO friends and family discount offer is a $30 \%$ discount on all items purchased. This $30 \%$ discount will allow AEO customers to shop at AEO during this event and receive the AEO friends and family discount.

\section{SELF-FOCUSED PROMOTIONS}

\section{PRAFERRED CUSTOMER SALE}

Private Sale Just for You!

\section{Preferred Customer Discount}

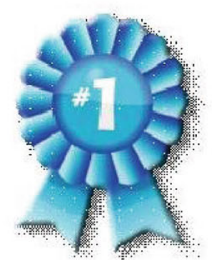

American Eagle Outfitters (AEO) has recently decided to offer a special discount to their best customers. This preferred customer discount will be offered to AEO customers during this event when AEO recognizes special customers.

This AEO Preferred Customer discount offer is a $30 \%$ discount on all items purchased. This $30 \%$ discount will allow AEO's customers like you to shop at AEO during this event and receive the $A E O$ Preferred Customer discount.
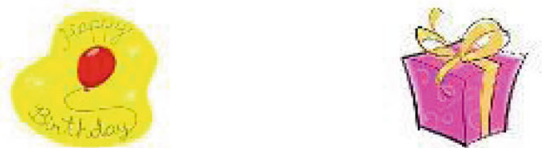

It's YOUR Day!

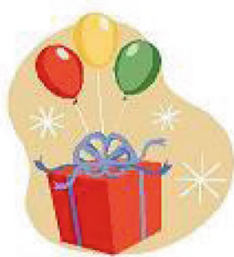
Happy Birthday Discount!!

A.mericon Eagle Qutfiters (AEO) has recently decided to offer a special birthday discount to individual customers. This discount wi: only be offered to individual customers during the month of the customer's birthday.

This individual customer binthday offer is a $30 \%$ discount on all ilems purchased, This $30 \%$ discount $W$ ill allow an individual customer to shop at AEO during the ir birthday month and recelve a special birthday discount.

\section{CONTROL PROMOTION}

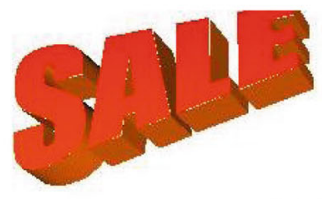

SALE!

American Eagle Outfitters (AEO) is having a sale. This sale will be available to everyone.

This sale will be a $30 \%$ discount on all items purchased. This discount will allow you to shop at American Eagle Outfitters and receive a $30 \%$ discount on your purchase. 


\section{References}

1. Aaker DA (1991) Managing brand equity. Harvard Business School Press, New York

2. Aaker JL, Lee AY (2001) “'I' seek pleasures and 'we' avoid pains: the role of self-regulatory goals in information processing and persuasion. J Consum Res 28(June):33-49

3. Agrawal N, Maheswaran D (2005) The effects of self-construal and commitment on persuasion. J Consum Res 31(March):841-849

4. Ahluwalia R (2008) How far can a brand stretch? understanding the role of self-construal. J Mark Res 45(June):337-350

5. Ahluwalia R, Burnkrant RE, Rao Unnava H (2000) Consumer response to negative publicity: the moderating role of commitment. J Mark Res 37(May):203-214

6. Ailawadi KL, Harlam BA, Cesar J, Trounce D (2006) Promotion profitability for a retailer: the role of promotion, brand, category, and store characteristics. J Mark Res 43(November):518-535

7. Ailawadi KL, Neslin SA, Gedenk K (2001) Pursuing the valueconscious consumer: store brands versus national brand promotions. J Mark 65(1):71-89

8. Barone MJ, Roy T (2010) Does exclusivity always pay off? Selffocused price promotions and consumer response. J Mark 74(2):121132

9. Barone MJ, Roy T (2010) The effect of deal exclusivity on consumer response to targeted price promotions: a social identification perspective. J Consum Psychol 20(1):78-89

10. Chandon P, Wansink B, Laurent G (2000) A benefit congruency framework of sales promotion effectiveness. J Mark 64(October):65-81

11. Cheema A, Patrick VM (2008) Anytime versus only: mindsets moderate the effect of expansive versus restrictive frames on promotion evaluation. J Mark Res 45(August):forthcoming

12. Cross SE, Morris ML, Gore JS (2002) Thinking about oneself and others: the relational-interdependent self-construal and social cognition. J Pers Soc Psychol 82(March):399-418

13. Duclos R, Barasch A (2014) Prosocial behavior in intergroup relations: how donor self-construal and recipient group-membership shape generosity. J Consum Res 41(1):93-108

14. Escalas J, Bettman J (2005) Self-construal, reference groups, and brand meaning. J Consum Res 32(December):378-389

15. Gardner W, Gabriel S, Lee A (1999) “'I' value freedom, but 'we' value relationships: self-construal priming mirrors cultural differences in judgment. Psychol Sci 10(June):321-326

16. Inman JJ, McAlister L, Hoyer WD (1990) Promotion signal: proxy for a price cut?". J Consum Res 17(June):74-81

17. Inman JJ, Peter AC, Raghubir P (1997) Framing the deal: the role of restrictions in accentuating deal value. J Consum Res 24(June):68-79

18. Jiang L, Hoegg JA, Dahl DW (2013) Consumer reaction to unearned preferential treatment. J Consum Res 40(3):412-427

19. Krishna A, Shoemaker RW (1992) Estimating the effects of higher coupon face values on the timing of redemptions, the mix of coupon redeemers, and purchase quantity. Psychol Marke 9(6):453-467

20. Krishna A, Zhang JZ (1999) Short- or long-duration coupons: the effect of expiration date on the profitability of coupon promotions. Manag Sci 45(August):1041-1056

21. Kuhn MH, McPartland TS (1954) An empirical investigation of selfattitudes. Am Sociol Rev 19(February):58-76
22. LeBoeuf RA (2006) Discount rates for time versus dates: the sensitivity of discounting to time-interval description. J Mark Res 43(February):59-72

23. Markus H, Kitayama S (1991) Culture and the self: implications for cognition emotion, and motivation. Psychol Rev 98(April):224-253

24. Monga AB, John DR (2007) Cultural differences in brand extension evaluation: the influence of analytic versus holistic thinking. J Consum Res 33(March):529-536

25. Moorman RH, Blakely GL (1995) Individualism-collectivism as an individual difference predictor of organizational citizenship behavior. J Organ Behav 16(2):127-142

26. Oyserman D, Coon HM, Kemmelmeier M (2002) Rethinking individualism and collectivism: evaluation of theoretical assumptions and meta-analyses. Psychol Bull 128(January):3-72

27. Oyserman D, Lee SWS (2008) Does culture influence what and how we think? Effects of priming individualism and collectivism. Psychol Bull 134(2):311-342

28. Preacher KJ, Hayes AF (2008) Asymptotic and resampling strategies for assessing and comparing indirect effects in multiple mediator models. Behav Res Methods 40(3):879-891

29. Raghubir P (1998) Coupon value: a signal for price?”. J Mark Res 35(August):316-324

30. Raghubir P (2004) Coupons in context: discounting prices or decreasing sales? J Retail 80(January):1-12

31. Raghubir P, Jeffrey Inman J, Grande H (2004) The three faces of consumer promotions. Calif Manag Rev 46(Summer):23-42

32. Shimp TA, Kavas A (1984) The theory of reasoned action applied to coupon usage. J Consum Res 11(December):795-809

33. Sinha I, Smith MF (2000) Consumers' perceptions of promotional framing of price. Psychol Mark 17(3):257-275

34. Singelis T (1994) The measurement of independent and interdependent self-construals. Personal Soc Psychol Bull 20(May):580-591

35. Strahilevitz M, Myers JG (1998) Donations to charity as purchase incentives: how well they work may depend on what you are trying to sell. J Consum Res 24(4):434-446

36. Swaminathan V, Page KL, Gürhan-Canli Z (2007) 'My' brand or 'our' brand: the effects of brand relationship dimensions and selfconstrual on brand evaluations. J Consum Res 34(August):248-259

37. Trafimow D, Triandis H, Goto S (1991) Some tests of the distinction between the private self and the collective self. J Pers Soc Psychol 60(5):649-655

38. Torelli CJ, Monga AB, Kaikati AM (2012) Doing poorly by doing good: corporate social responsibility and brand concepts. J Consum Res 38(5):948-963

39. Winterich KP, Barone JM (2011) Warm glow or cold, hard cash? social identity effects on consumer choice for donation versus discount promotions. J Mark Res 48(5):855-868

40. Winterich KP, Mittal V, Ross WT Jr (2009) Donation behavior toward in-groups and out-groups: the role of gender and moral identity. J Consum Res 36(2):199-214

41. Wyant C (2007) Promotion lifts Christopher and Banks' sales. Minneapolis/St. Paul Bus J 8

42. Yoo B, Donthu N, Lee S (2000) An examination of selected marketing mix elements and brand equity. J Acad Mark Sci 28(Spring):195-211

43. Zhao X, Lynch JG Jr, Qimei C (2010) Reconsidering Baron and Kenny: myths and truths about mediation analysis. J Consum Res 37(2):197-206 